\title{
THE DESIGN OF THE UNIVERSITY ELECTRONIC CURRENCY SYSTEM USING BLOCKCHAIN-BASED TECHNOLOGY
}

\author{
Hyun Joo Kim ${ }^{1}$ and Min Sun Kim${ }^{2 *}$ \\ ${ }^{1}$ Department of Electronic \& Electrical Engineering, Dan-Kook University, Korea \\ ${ }^{2}$ College of Global Business Administration, Hyupsung University, Korea \\ ${ }^{1}$ chopinkhj@gmail.com, ${ }^{2}$ sunnyminkim@ hanmail.net
}

\begin{abstract}
The local currencies of South Korea were first adopted in 1997 after the economic crisis as a method to vitalize the local economy; subsequently, the currencies showed a movement. However, these local currencies have reached their operation limits owing to limited local market size and unguaranteed continuity of investment, and yet, they still exist. Meanwhile, overseas cases, namely the European Regional Development Fund (ERDP) in the European Union, SoNates in France, Bristol Pound in Bristol in the UK, Silvio Gegell in Austria, and WIR in Switzerland have stably settled as independent local currencies to promote local economy and prevent the outflow of capital and WIR in Switzerland has over 80 years of history, and it stands as an excellent example of an independent local currency that has been established to prevent the outflow of capital from a country. A characteristic of local electronic currencies such as Zeropay, Gimpopay, and Nowon Cash, which have recently become well-known, is that they are produced and used as blockchainbased local currencies in only certain regions. In the system proposed here, when transactions are initiated, multiple proof-of-transaction servers (nodes) coordinate to verify the data, which are in turn saved in the blocks of each server and ultimately saved into the blockchain database. In the blockchain database, only the transaction history verified by blockchain nodes in the network can be modified. The blockchain database used for this process is configured using one of the proofof-transaction servers in the network installed in advance. This study designed a blockchain-based in-house electronic currency that can be used at an organization only.
\end{abstract}

\section{Keywords - Blockchain, Electronic Currency, University of Electronic Currency}

\section{INTRODUCTION}

The use of blockchain-based local currency, such as Zeropay, Gimpopay, and Nowon Cash, is increasing. The local currencies of South Korea were first adopted in 1997 after the economic crisis as a method to vitalize the local economy; subsequently, the currencies showed a movement. The local currencies adopted at that time were operated mostly for vitalization of communities and local economies. However, these local currencies have reached their operation limits owing to limited local market size and unguaranteed continuity of investment, and yet, they still exist [1]. Meanwhile, overseas cases, namely the European Regional Development Fund (ERDP) in the European Union, SoNates in France, Bristol Pound in Bristol in the

Received: May 6, 2019

Reviewed: July 15, 2019

Accepted: August 7, 2019

* Corresponding Author 
UK, Silvio Gegell in Austria, and WIR in Switzerland have stably settled as independent local currencies to promote local economy and prevent the outflow of capital. In particular, WIR of Switzerland boasts over 80 years of history and has now grown to become an independent local currency that is used by $20 \%$ of small and medium companies in Switzerland [2]. As another example, Alipay of China was developed to enable customers to make payments easily and conveniently when purchasing products from Alibaba, a Chinese e-commerce company. Afterwards, Alibaba launched Ant Financial and then established MyBank, an Internet bank, thereby facilitating the growth of Alipay at its core. Owing to its explosive growth, Alipay has overtaken eBay in China and has now grown as a worldwide electronic currency. In South Korea, Alipay is currently used as an income source from Chinese tourists, and $95 \%$ of Chinese tourists have already started using the Alipay payment system [3]. This means that Alipay has deeply implanted itself in South Korea as well. This raises the question of the use of South Korean electronic currencies. Zeropay, Gimpopay, and Nowon Cash, which are well known to us, can be cited as examples. A characteristic of these local electronic currencies is that they are created and used as blockchain-based local currencies. The Korean central government is attempting to foster blockchains by placing the local currencies at its forefront. However, their growth rate is relatively weak compared to the outstanding examples from overseas. Nonetheless, they are attracting attention as a technology that will innovate in economic and social areas. This is because their strength caught people's attention: they are local electronic currencies that use blockchain, which is a technology gaining attention globally. In the case of South Korea, blockchains are spreading quickly across entire industries such as electronic cash, e-commerce, and public services, with a focus on the financial sector. The interest in the mentioned local currencies is growing explosively because they are blockchain-based cryptocurrencies. People have high hopes for their innovativeness because they present a "trusted network technology" that facilitates direct transactions between individual persons without a broker in our ultra-modern society, where the trustworthiness of other parties cannot always be verified.

This study used the blockchain to explore the possibility of using in-house electronic currency in an organization. The safety and credibility of conventional in-house local currency were ensured based on the distributed ledger, transparency, and shared ledger concepts of blockchain. Using these strengths, an in-house electronic currency for an organization was designed as a blockchain-based electronic currency and its potential was investigated. Furthermore, this was applied on a university campus, because the university had many places such as selfoperated stores and commuting buses where the currency could be used. The blockchain-based in-house electronic currency was designed to facilitate cash issuance, cash transaction, cash settlement, and donations.

\section{RELATED WORKS}

\subsection{CONCEPT OF BLOCKCHAIN}

The Blockchain is a method of distributing and storing data in bundles and blocks across all nodes participating in a data transaction. Thus, transaction information is not stored in a central server but distributed among various computers attached to different networks [4]. Blockchain is based on ledger sharing, tamper prevention, and reliability. Ledger sharing of blockchain refers to sharing transaction ledgers with the nodes and participants of all networks involved. Therefore, transactions are possible only in a distributed (P2P) network environment. Transaction records in a blockchain are owned by all the network participants, and therefore they cannot be modified. The existing 
transactions can only be modified by a chain of blocks connected to the blockchain, thereby preventing tampering of transaction data and ensuring integrity. In other words, blockchain is highly reliable because the process of reading, inputting, and handling data is integrated through data sharing by the participants of multiple networks and approved by multiple agreements [4]-[8].

\subsection{TYPES OF BLOCKCHAIN}

Blockchain is classified into three blockchain types known as public blockchains, private blockchains, and consortium blockchains depending on the characteristics of the network participants and the scope of system access. In 2013, Vitalik Buterin was able to process all types of contracts using blockchain technology for financial transactions such as payment, settlement, and transfer. This was the origination of Smart Contracts. Initially, Buterin unsuccessfully attempted to implement Smart Contracts by modifying a part of Bitcoin. He only achieved success by creating a cryptocurrency called Etherium and implementing Smart Contracts through forking Bitcoin. We have named this Blockchain 2.0. Blockchain 2.0 technology allows developers to modify contract terms and content directly. Thus, in principle, it allows users to implement all types of contracts on the Etherium platform. However, it is not easy for members of the general public to modify Smart Contracts directly because they would need to be familiar with the Javabased development language called Solidity. Table I shows the comparison and analysis results for each type of Blockchain [2].

Table I. Blockchain Type

\begin{tabular}{|c|c|c|c|}
\hline Division & Public & Privacy & Consortium \\
\hline Management & All node & Center Authority & $\begin{array}{c}\text { Consortium od } \\
\text { Member node }\end{array}$ \\
\hline Data Access & Any way & \multicolumn{2}{|c|}{ Authorized User } \\
\hline Speed & $\begin{array}{c}\text { Extension is } \\
\text { Difficult }\end{array}$ & $\begin{array}{c}\text { Extension is very Easy. } \\
\text { Fast }\end{array}$ & $\begin{array}{c}\text { Expansion is } \\
\text { Easy. }\end{array}$ \\
\hline $\begin{array}{c}\text { Proof of } \\
\text { Transaction }\end{array}$ & $\begin{array}{c}\text { Anonymous } \\
\text { Transaction }\end{array}$ & $\begin{array}{c}\text { Possible by Central } \\
\text { Control }\end{array}$ & $\begin{array}{c}\text { Possible According } \\
\text { to Pre-Agreed Rules }\end{array}$ \\
\hline Identification & Anonymous & \multicolumn{2}{|c|}{ Identifiable } \\
\hline $\begin{array}{c}\text { Security } \\
\text { Currency }\end{array}$ & Need, Using & Unnecessary, Unused \\
\hline Utilization & Bitcoin & Stock Exchange & Hyperledger \\
& Idolium & \multicolumn{2}{|c|}{} \\
\hline
\end{tabular}

\subsection{FEATURES OF THE BLOCKCHAIN}

A blockchain has such properties as decentralization, efficiency, scalability, transparency, security, safety, irreversibility, and immutability. Because a blockchain makes data transaction possible without a third party in a reliable and decentralized network environment, it can reduce the costs incurred because of transaction fees. Because it is decentralized, unnecessary maintenance costs are reduced as well, and the use of a public source makes the system scalable, inviting participation from anyone. This allows the reduction of IT system implementation costs. The transparency of the blockchain means that all transaction history is managed in a public manner, with the data jointly possessed by all network participants. This improves security and guarantees data integrity and prevention of data manipulation. Another advantage of the blockchain is that errors and performance degradation in a participating network system do not affect the overall network. More than anything, records cannot be modified or cancelled, which ensures their accuracy $[7,8]$. 


\subsection{BEHAVIOR OF BLOCKCHAIN}

A blockchain generates a block when a transaction request is received. Simultaneously, every node on the network shares this information and, after receiving permission from a majority, a temporal relationship is made with an existing prior block, thereby linking a chain. As for data blocks, when content of prior block is changed because a prior block and a succeeding block become linked, the blocks linked thereafter must all be regenerated. Therefore, when a change is made in data, all content of past blocks must be modified. The operation of the blockchain is classified into stage 1: transaction, stage 2: block, stage 3: chaining, and stage 4: propagation. The data transmission in Fig. 1 shows the transaction stage, the first stage, which is process of generating an additional block. The second stage, which is the block stage, is a process of determining the validity of data at the participating nodes on the network and getting permission. The third stage, chaining, ultimately links blocks in a chain whereby a block forms a temporal relationship with the prior block. Lastly, the fourth stage, propagation, distributes and stores the blocks in participating nodes on the network [9],[10]. Table I shows the comparison and analysis results for each type of blockchain.

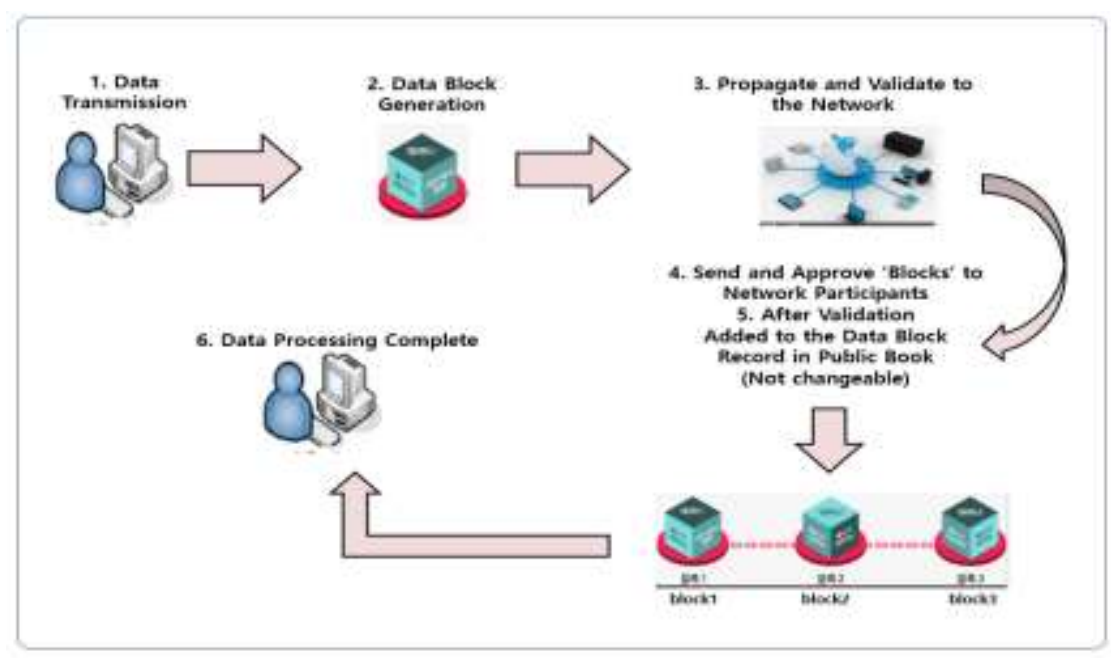

Fig. 1 Blockchain of Operation Principle

\subsection{CRYPTO-CURRENCY AND BLOCKCHAIN}

Numerous financial institutions have bankrupted owing to the subprime mortgage crisis of 2007. The entire world faced the financial crisis, as evidenced by the world's biggest bankruptcy of Lehman Brothers in September, 2008 at the beginning of financial crisis. However, the individuals responsible for the problem overcame the crisis through the bailout program while devastating the lives of ordinary citizens. Afterwards, they received millions of dollars in bonuses and the problematic system was still intact. In other words, they were exercising more influence than ever. At that time, the cryptocurrency bitcoin emerged. In comparison with the centralized financial system, bitcoin was a type of experiment that could perform same functions as a conventional currency, such as issuing and transacting money, assuming that ledgers could be saved on numerous computers and validated with each other based on the encryption technology. The bitcoin became known as a blockchain whitepaper presented by Satoshi Nakamoto in 2009. Blockchain is a technology applied for the safekeeping of transaction content involving bitcoin. A blockchain records various transactions for public record and the participating nodes are linked to possess these records in a chain. Blockchain is a technology that uses an algorithm to verify whether the records are correct and the 
transactions are valid, and it creates an ecosystem to maintain them. Such blockchain technology was used to create cryptocurrency, the first of which was Bitcoin. In general, Bitcoin is produced by cryptomining, which, if successful, generates a block through the consensus process. Thereafter, the block is connected to other blocks in the front and back to form a chain. Coins are provided as a reward for this cryptomining process, which constitutes the general mining process for Bitcoin $[11,12]$.

\subsection{IN-HOUSE ELECTRONIC CURRENCY}

Electronic currency offers following benefits: decreased need to possess paper money, reduction of various fees for financial transactions, decreased transaction cost through direct transactions with a seller, less risk of theft and loss owing to simplification of keeping money. South Korean electronic currencies include K-cash, Mybi, Visacash, and T-money. In addition, representative local electronic currencies include "Dooroo, Ari, Neulpoom", "Songpa money", "Eupyeong e-poomasi", "Seongnam Nuri", and education currency "Mindeulrae". These are all in-house local electronic currencies used only in certain areas. In South Korea, some local governments and nonprofit private organizations have produced them, and there are currently about 30 currencies in circulation. The local currencies of South Korea have a short history. At the time of the financial crisis in 1998, some nonprofit organizations and local governments attempted to use them on a small scale to tackle unemployment. The local currencies of South Korea commenced based on a method of issuing the money used between members, and they are currently operated as a system whereby accounts can be opened and goods and services are provided and received between members without using actual money. Local currencies that emphasize an intention of sharing economy with a slogan, "benefits are given to each other through the sharing of goods and talents" stand out. They are mostly operated as a system in which goods and services are exchanged through the money used exclusively in a certain region. Additionally, apart from actually printing and circulating money, the use of the passbook account method is increasing [13]. In principle, an inhouse electronic currency can be used within an organization, and in accordance with this, there is a case for implementing it in a university. In that university, electronic cash and cyber money linked with financial institutions can be used as an in-house electronic currency [9]. University A, a Korean academic institution, jointly operated K-Cash with Bank N. University A received identification cards issued by Bank $\mathrm{N}$ and converted money from an account at Bank $\mathrm{N}$ into an electronic currency used at the university. University B used electronic currency through prepaid transportation cards. University C, which utilizes a cyber money system, stored its electronic currency in a server, rather than in smart identification cards $[14,15]$.

\section{THE DESIGN OF THE UNIVERSITY ELECTRONIC CURRENCY SYSTEM USING BLOCKCHAIN-BASED TECHNOLOGY}

\subsection{OVERVIEW OF THE PROPOSED SYSTEM}

Based on blockchain, this study designs an electronic currency that can be used in a particular organization or private region. We call it an in-house electronic currency or local private electronic currency. In this study, the design was applied to a university system, and the proposed system was developed by using private blockchain. Because inhouse electronic currency is used only within an organization, the following four basic money processes are performed: money issuance, transaction, payment, and settlement.

The proposed system is designed in conjunction with an organization's donation system so that electronic money can be automatically donated during payment processing of electronic money. 


\subsection{DESIGN OF THE PROPOSED SYSTEM}

The overall structure of the proposed system for processing an in-house electronic currency based on blockchain is as follows. The in-house electronic currency based on blockchain is charged into each individual's electronic wallet at the currency charging station as a reward for the student's labor service in the university. If the cryptocurrency is $100 \mathrm{hw}$ (Hyupsung Won), it has the same cash value as 100 won. Students can generate transactions using the electronic currency in their electronic wallets at the shops in the university. The shops receive the cash later after deducting a certain fee through the adjustment process. Therefore, the four processes currency issuance, transaction, settlement, and adjustment are used as the fundamental flow of the in-house electronic currency based on blockchain. In general, the production process of bitcoin, which is a cryptocurrency, is as follows. Encryption mining is performed, and after its successful completion, a block is generated through an agreement process. Then when prior and next blocks are linked, a chain is formed.

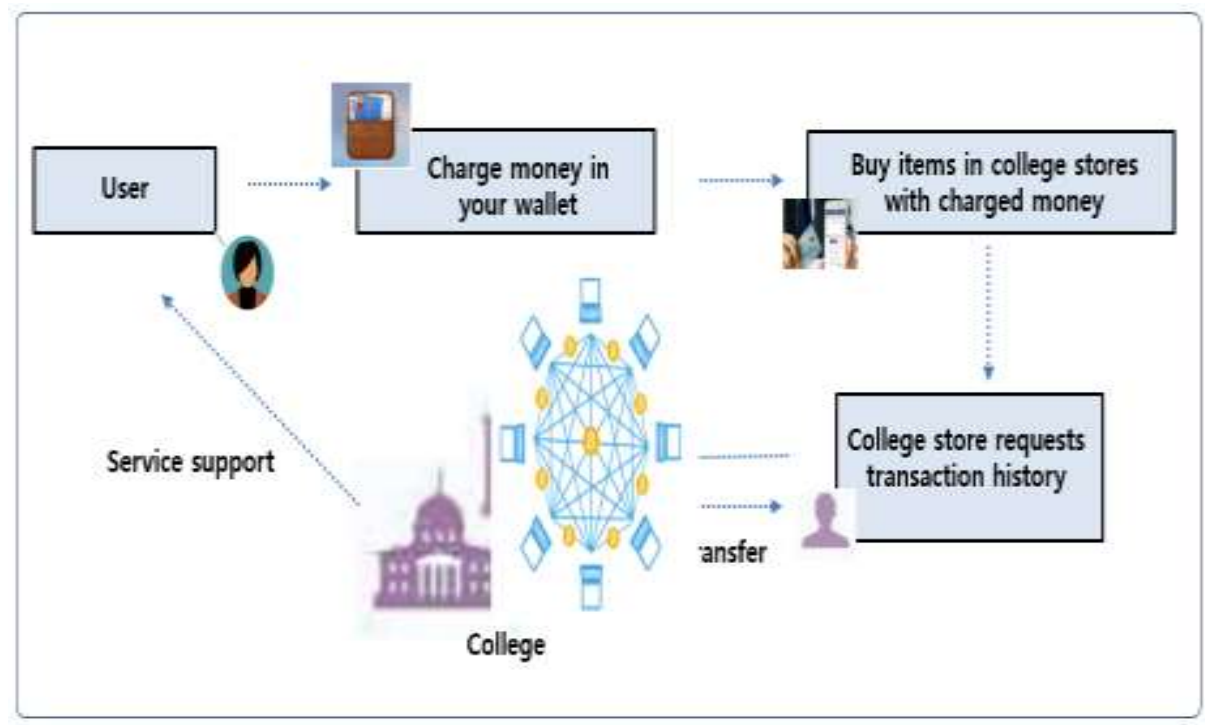

Fig. 2 Proposal System Electronic Currency Flow

The proposed system does not use the bit process such as bit coin. In relation to the currency issuance of the proposed system, the university's currency issuing department charges individual electronic wallets with the electronic currency. The charged electronic currency can be used at various shops in the university, and the shops involved in these transactions will pay a $0.15 \%$ fee to the electronic currency operation support fund through the electronic currency adjustment process. In addition, the students using the electronic currency can check the places in which they used their electronic currency and can enquire into the flow of the currency used. And students can view the flow of money and also support web services. The following [Figure 2] is a flowchart of the electronic currency processing of the proposed system. The user can charge money in his/ her electronic wallet and pay the charged electronic currency at each store in the university. Each store in the university deducts electronic currency from its POS system. The blockchain is used for transactions made during this time, payment and settlement for students and stores, stores and universities.

\subsubsection{STRUCTURE OF THE PROPOSED SYSTEM}

The proposed system consists of users, mobile devices, authorized user nodes, an electronic currency transaction database, and a user application database. A user issues 
and recharges electronic money on his or her mobile device. The electronic money recharged on the mobile device is created and stored in the shape of a block. The user can then use this electronic money by completing the verification and approval processes of the electronic money balance at a permitted node on the network. The verification process verifies the validity by sending and receiving data to and from the authorized user when connected to a mobile device. Once the transaction is completed, the store's POS system sends the transaction details to the user and transaction databases. The following Fig. 3 is a service flowchart of the proposed system.

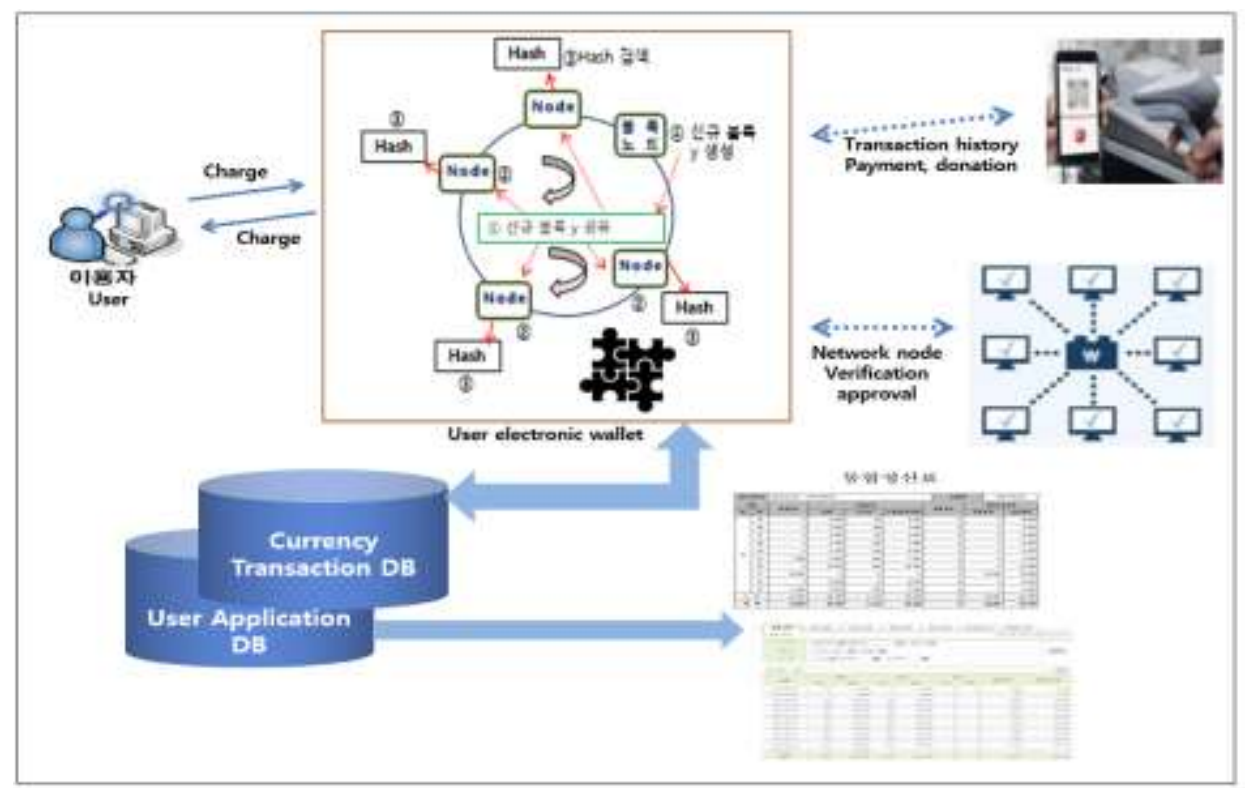

Fig. 3 Proposal System Service Flow

\subsubsection{DESIGN OF THE PROPOSED SYSTEM}

For in-house electronic currency to be used with the proposed system, electronic money is first issued. For users, in-house electronic money can be issued as both card and mobile types; in principle, the mobile type is basically used.

In Fig. 4, flow (1) shows the main screen of in- house electronic currency issued from a mobile device for a user after the user logs in (i.e., by entering an ID and password). When the user logs in, a QR (Quick Response) code is displayed, as shown in the upper part of the flow (2) screen in Fig. 4. Mobile phone screen by touching the QR code main, the user can see thebalance of money, as shown in flow (3). A specific amount of inhouse electronic money can be recharged at a corresponding POS (Point of Sales) by reading a QR code. This money can then be used to make a payment at a corresponding store, as shown in flow (3) of Fig. 4. When the money balance changes because of recharge or use, it is displayed on the app's screen immediately after recharge (transaction). Because the development fund donation is a type of transaction, a specific amount of in-house electronic money can also be donated to the development fund at every university store. This system is configured to register the development fund as a fund category to facilitate donations automatically when it is selected at a transacted store. The transaction details and settlement of in-house electronic currency can be checked on the POS and corresponding Web systems for each university store. Based on the checking process, the stores can demand cash payments from the university. 


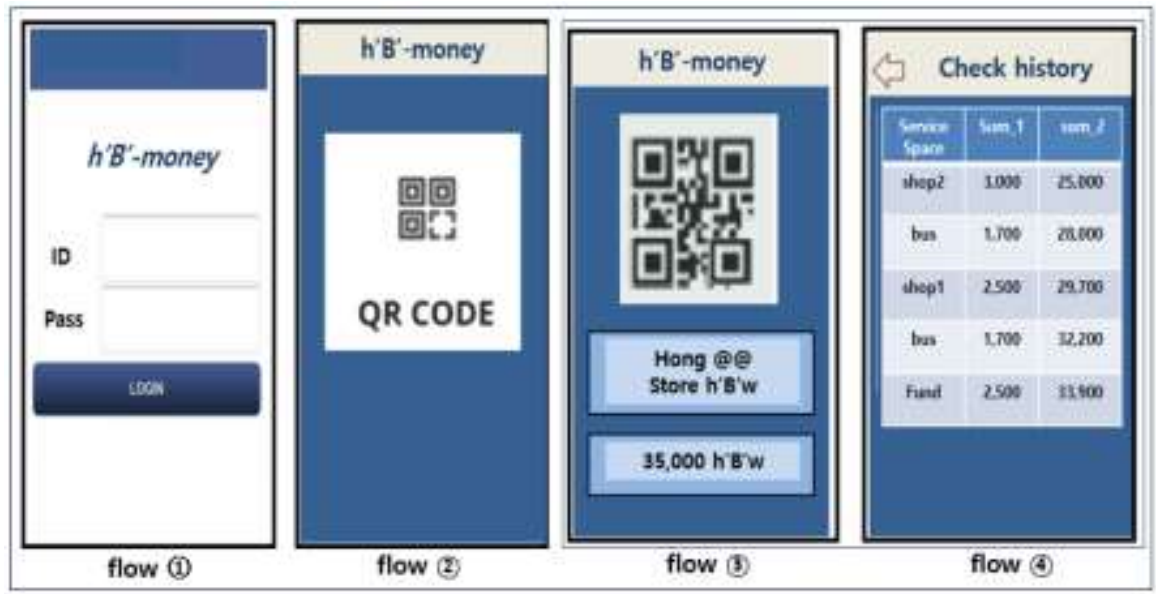

Fig. 4 Proposal System Service Screen

\subsubsection{STORING A DATA BLOCK IN THE PROPOSED SYSTEM}

Data storage in the proposed system is classified into: storage of currency transaction details and storage of a transaction detail database for the store's POS system operation. The currency transaction details of users are stored in user blocks. When a user accesses electronic currency, the electronic currency balance is verified at a pre-authorized node on the network and, when approved, it can be used. The pre-authorized node on the network becomes a participating node when it is configured as an affiliated member and when the use of electronic currency is authorized.

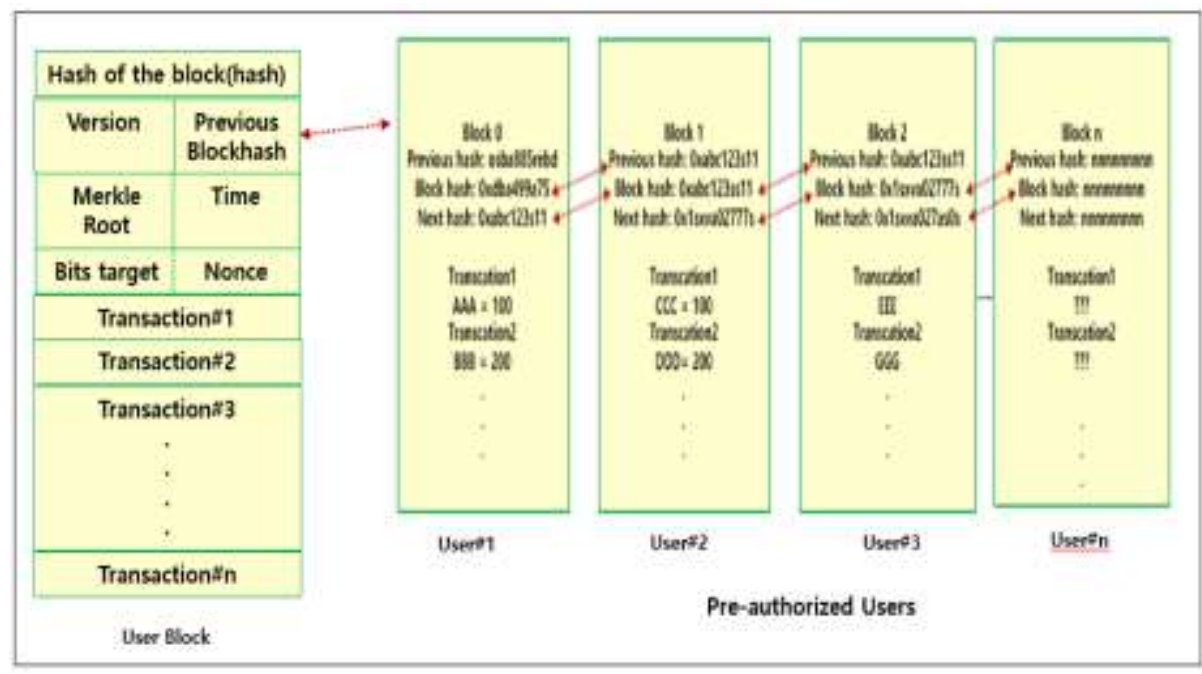

Fig. 5 Electronic Currency Block Structure of Proposal System

Figure 5 shows the user block information used in the proposed system with a blockchain structure. Figure 5 depicts the blockchain structure. Blocks in blockchain are composed of a header and a body. The header contains hash data of the previous block, current block, and next block. The body stores transaction history. Blocks are searched through an index. That is, the block header of user 3 contains information about user 2 and user4; user2's block contains block data of user1 and user3. In sum, these blocks are connected in a chain form. 


\section{CONCLUSION}

Blockchain is increasingly being applied in various industries. Interest in cryptocurrency and the number of organizations using it for local currency are also increasing. The reason blockchain is attracting attention across whole societies is because IT service can be implemented in-house by using P2P without a centralized main computer with respect to people's working habits, means of developing and conducting business, and methods of constructing IT ecosystems. Furthermore, blockchains are of particular interest because it is perceived as a successful example of constructing an IT information service ecosystem using P2P. A characteristic of local electronic currencies such as Zeropay, Gimpopay, and Nowon Cash, which have recently become well-known, is that they are produced and used as blockchain-based local currencies in only certain region (One Organization). The interest in the mentioned local currencies is growing explosively because they are blockchain-based cryptocurrencies. People have high hopes for their innovativeness because they present a "trusted network technology" that facilitates direct transactions between individual persons without a broker in our ultra-modern society, where the trustworthiness of other parties cannot always be verified.

This study designed a blockchain-based in-house electronic currency that can be used at an organization only. This study applied the basic principles of blockchain to a university system and developed a blockchain-based electronic currency for use at a university. We then described how this electronic currency can be operated and managed in-house while ensuring transparent asset management for members and promoting the use of electronic currency in an organization. The blockchain database used for this process is configured using one of the proof-of-transaction servers in the network installed in advance, thereby supporting the blockchain transaction history. The system is configured so that users cannot find the database server containing the author of the final transaction history. In addition, the final blockchain database server is operated by periodically changing its configuration in the network server. The blockchain database used for this process is also configured using one of the proof-of-transaction servers installed in advance, thereby supporting the blockchain transaction history. The system is configured so that users cannot find the database server containing the author of the final transaction history.

This study also demonstrated that blockchain technology, which is leading the business industry, can lead to the creation of new businesses at universities. Finally, because it does not require considerable IT cost or a large-scale infrastructure as compared to conventional electronic currencies, it is expected to assist collage electronic currency operators.

\section{REFERENCES}

[1] Kwon, Gyun Bo, "A Study on the Local Currency Operating Mode Based on Mobile Platform SystemFocused on Gyeonggi Province", Dankook University, (2019).

[2] Gyeonggi Research Institute, "Issue and Challenges of Local Currency for Local Currency Activation" No. 323, (2018).

[3] CHEN LUNING, "Research on the Utility of Alipay in International Settlement", Kangwon National University, (2016).

[4] Kim H.J., and Kim M.S., "Design of an In-house Cryptocurrency Information Service Based on Blockchain", International Conference on IT Applications and Management, Feb (2019).

[5] Yoo S.M., "Policy Direction for Block Chain", Information and Communication Center, (2017).

[6] Kil S.W., "Changes in Service Platform Due to Blockchain and Trends and Implications of Virtual Money Marker", National IT Industry Promotion Agency, Issue Report, Vol. 19, (2017).

[7] Bipi Technology Trading, "Block Chain Industry Map Changes", (2017).

[8] Bipi Technology Trading, "It changes the industrial map of blockchain \& A Study on the Block Chain Market and the State of National Policies and Regulations", (2017): 14-17. Available From: ISBN 9791187327950/1187327956. 
[9] Moon S.G., Kim M.S., and Kim H.J., "Design of an Integreated University Information Service Model Based on Block Chain", Korea Academia-Industrial Cooperation Society, Vol. 20, No. 2, (2019): 43-50. https://doi.org/10.5762/KAIS.2019.20.2.43

[10] Kim H.J. and Kim M.S., "Design of Block Chain Based Education Information Service Platform Module", Korea Academia-Industrial Cooperation Society Fall Conference, Vol. 19, No. 2, (2018): 456459.

[11] Kwak J.H, "A conceptual model of crypto-currency for travel using a blockchain consensus mechanism", International Journal of Tourism and Hospitality Research, Vol. 33, No. 3, (2019): 143154. DOI: https://doi.org/10.21298/IJTHR.2019.3.33.3.143

[12] Kim J.S, "The Korean Society of Computer and Information", Journal of the Korea Society of Computer and Information, Vol, 24, No. 2, (2019): 67-74. DOI: https://doi.org/10.9708/jksci.2019.24.02.067

[13] Kim J.S., "Our Town has 'Local Currency' ", Next Economy, (2013). DOI: http://www.nexteconomy.co.kr/news/articleView.html?idxno=8025.

[14] Kim H.J., Lee S.J., and Shin I.C., "Design and Implementation of In-house Electronic Money using Java Cards", International Journal of Smart Home, Vol, 7, No. 5, (2013): 103-114. DOI: http://dx.doi.org/10.14257/ijsh.2013.7.5.11.

[15] Kim H.J, Lee S.J, Shin I.C, "In-House e-currency Technology and Application Cases”, KMIS \& Pacific Asia Conference on Information systems(PACIS), (2013). 